\title{
O compartilhamento de obras científicas na internet
}

\author{
LUIZ GONZAGA SILVA ADOLFO, \\ IEDA ROCHA e LAURA LUCE MAISONNAVE
}

"A 'pirataria'é o seu primeiro contato com o trabalho do artista. Se a ideia for boa, você gostará de tê-la em sua casa; uma ideia consistente não precisa de proteção. O resto é ganância ou ignorância."

(Coelho, 30 maio 2011)

\section{Introdução}

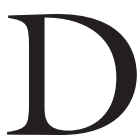

ELICADO é o tema proposto, mas sua abordagem é pertinente às portas da reforma da legislação autoral brasileira. Haveria como a legislação conjugar os interesses do autor da obra científica com os do interesse público? A reflexão acerca da dicotomia entre o interesse público e o direito autoral remonta à discussão sobre a prevalência de princípios constitucionais. De um lado, tem-se o direito de acesso à educação e à cultura, previsto na Carta Maior em dois dispositivos: primeiramente, no artigo 205, que concebe a educação como um direito de todos, um dever do Estado e da família e, logo em seguida, no artigo 215, que declara que o Estado garantirá o acesso dos cidadãos à cultura. A seu lado, figura, ainda, o direito de acesso à informação, consignado no inciso XIV do artigo 5o da Constituição Federal. Tais garantias constitucionais consistem em limitadores dos direitos autorais. Nesse sentido, na dicção de Reis (2008, p.159), o viés puramente individualista que marca as vertentes do direito autoral deve ser remodelado diante da realidade social e jurídica do Brasil a exigir que, sobretudo, os institutos privados atendam à funcionalidade social.

O fato é que o compartilhamento das obras científicas no ambiente virtual, de forma coletiva ou, mesmo, peer-to-peer, gera uma tensão e exaspera muitos titulares de direitos autorais e doutrinadores, como Cabral (2009, p.121-2), para quem a tutela jurídica das obras intelectuais na internet deve observar o rigor da Lei Autoral (Lei n.9.610, de 1998) vigente. Essa tensão justifica-se porque um único compartilhamento pela web pode ensejar muitos outros, em múltiplos formatos, como o impresso ou o reproduzido em diversos meios tecnológicos: pendrives, CD e Bluetooth. Os editores temem cair no ostracismo, considerando que, alheios a essa nova forma de disponibilização de conteúdo, estariam fora da cadeia produtiva.

É bom pontuar que a referida lei, no inciso I de seu artigo 46, permite a reprodução de pequenos trechos de um único exemplar de uma obra literária 
ou científica para o uso privado do copista, desde que feita por ele próprio e sem visar lucro, inexigindo a autorização do titular dos direitos autorais. No entanto, a mesma lei impede que uma coletividade, como a composta por uma universidade, por exemplo, usufrua dessa limitação ao direito autoral, o que parece incompatível com a dinâmica e a velocidade proporcionadas pela internet e impostas pela teia virtual em que seus usuários estão inseridos. Aliás, esse é o objetivo da rede mundial de computadores: o compartilhamento de dados, de informações, de ideias, tudo de forma interativa e dinâmica. Para Lemos (2005, p.36), a fim de se manter forte e ágil, a cultura, necessariamente, precisa dialogar com outras formas culturais. Foi assim desde as culturas primitivas e esse modo de proceder perdura até a contemporaneidade, no que se chama de cibercultura. Não há como voltar atrás na linha do tempo e negar o desenvolvimento tecnológico: a legislação exige, urgentemente, uma adaptação à complexidade do sistema social, que hoje está organizado na rede informacional, aos moldes dos Princípios Constitucionais do Estado Democrático de Direito que o norteia. No entanto, como restará demonstrado, a redação final da reforma da Lei Autoral pode estar conduzindo a um retrocesso no atinente às limitações de direitos de autor, na medida em que as diminuiu na construção do texto, após submissão à consulta pública, fato que destoa da intenção do legislador constitucional.

Inconcebível é negar a realidade social de que o compartilhamento coletivo - não só de obras científicas, mas também das de outra natureza - tem sido reiteradamente praticado pelos usuários da rede mundial de computadores. Se tal compartilhamento for realizado com finalidade didática, educacional, de forma individual ou coletiva, ainda que de texto integral, parece razoável que seja legalmente admitido. Mas, infelizmente, o texto final da reforma não contempla essa possibilidade. E a legislação, mais uma vez, já nasce em dissonância com a necessidade social, dando as costas ao interesse público cujo norte nunca deveria deixar de mirar. Nessa senda, Aronne (2006, p.95) esclarece que é chegada a hora, ainda que tardia, do implemento ao direito da propriedade intelectual de uma nova base teórica sem vinculação com a clássica teoria do direito privado.

\section{Da divulgação auferida pelo autor científico com a difusão acessível de suas obras na internet e a (re)compensa pela falta de pagamento da obra}

A ampliação das limitações a esses direitos do titular de direitos autorais das obras científicas, na internet, recompensa, em parte, a falta de pagamento, na medida em que projeta e solidifica seu perfil como intelectual, cientista ou técnico. O sujeito de direitos autorais possui características muito peculiares, uma vez que publica obras que contribuem na formação cultural e acadêmica de seus leitores e, mormente, porque essas geram conhecimento derivado daquilo que produz e proporcionam sua propagação. Nesse diapasão, fica evidente que, por agregar valor à trajetória acadêmica do autor, o compartilhamento gratuito de conteúdo científico no ambiente virtual exige muito mais a garantia da prote- 
ção de seus direitos morais. Assim, considerada a natureza do suporte em que o conteúdo é reproduzido, resta inócuo idealizar a proteção dos direitos patrimoniais de forma tradicional. Isso, no entanto, não significa dizer que o autor não será remunerado; ao contrário, há um nicho de mercado a ser explorado e, pelo próprio autor, sem intermediários. Ascensão (2011, p.12) clarifica essa ideia, explicando que acesso livre não é sinônimo de acesso gratuito.

Nesse ponto, há que destacar uma peculiaridade em relação ao compartilhamento de obras na internet: o autor que, comumente, cede seus direitos de editar, imprimir e comercializar sua obra à indústria editorial, na produção convencional de livros impressos, não necessita de intermediários. O produto chega com muito mais facilidade às mãos do leitor, e os custos de produção de uma obra em formato digital são severamente menores do que os custos da edição impressa. Esse é um ponto nevrálgico no conflito de interesses entre os direitos privados e o interesse público. Mas é interessante observar o que identificaram Machado \& Ortellado (2006, p.11): a permissão de acesso e de realização de cópias sem fins lucrativos não impediu o crescimento e a sedimentação das editoras no Brasil, sendo possível a coexistência de uma indústria comercial de livros impressos com a liberdade de cópia. Portanto, o argumento de que o mercado editorial e, em via reflexa, o autor restariam prejudicados com a disponibilização de suas obras, como aqui é proposto, não se sustenta. Ressalte-se que a produção intelectual, na sociedade da informação, está inserida num contingente alheio ao da economia tradicional, que sucumbe aos recursos financeiros escassos e está calcada na transformação de matérias-primas em produto final, no modelo industrial convencional, superado pela tecnologia da informação que, segundo Castells (2001, p.68), produz, na atualidade, uma revolução de idêntica importância à da Revolução Industrial. $\mathrm{O}$ valor agregado a esse tipo novel de produto não é palpável, mas nem por isso é menos importante. Ainda, para Castells (2001, p.69), cada vez mais e numa velocidade cada vez maior, a nova tessitura social permite que as informações, portadoras de conhecimentos que outrora seriam de acesso restrito e caro, se integrem num grande sistema comum, a custos módicos.

Sem um olhar acurado sobre a questão, a disponibilização de obras na internet aponta para grandes prejuízos aos autores. No entanto, uma disponibilização bem planejada amplia o alcance da obra, gerando benefícios ao autor por meio de seu reconhecimento mais rápido e capilar. Segundo Negroponte (1997, p.218), a tecnologia digital vem a ser uma força natural que conduz as pessoas a uma maior conexão, e a capacitação que a vida digital propicia é benéfica tanto ao indivíduo quanto à sociedade.

A legislação brasileira em vigor sobre os direitos autorais, em seu artigo 7으, parágrafo $3^{\circ}$, faz distinção entre obras artísticas, literárias e científicas. Assim, já havendo previsão legal expressa confirmando um tratamento diferenciado entre as obras citadas, entende-se, pelo caminho da lógica, que tal diferenciação deva ser aplicada, também, no campo virtual. Então, sendo respeitados todos os direi- 
tos morais do autor, seria flexibilizada a concepção dos direitos patrimoniais - e não os direitos patrimoniais em si, garantindo-se a remuneração ao autor, porém, de maneira diversa à vivenciada por intermédio do tradicional contrato de cessão de direitos ao editor com relação à publicação na internet, mantendo-se estes últimos hígidos com relação às obras físicas. Toda a produção gráfica envolve, pois, a utilização de recursos financeiros para a aquisição da matéria-prima que faz parte da cadeia de produção, como papel e tinta, e o salário dos funcionários que trabalham na gráfica, na editora, o que é repassado ao consumidor final. Justifica-se, assim, que haja uma retribuição pecuniária por esse tipo de obra, a qual é, em verdade, destinada em grande parte aos cofres dos editores - que publicam, divulgam e comercializam a forma gráfica de livro - e, num percentual bem inferior - normalmente de $10 \%$ do valor de capa do livro -, ao autor.

É certo que quem se dedica à produção acadêmica está vinculado a um ideal associado ao fomento da educação, da cultura e do desenvolvimento social. Essa categoria de escritores não depende da venda de exemplares impressos como única fonte de renda, mas preza para que, mais do que a venda de exemplares em formato de livro impresso, sua obra lhe seja fonte de prestígio e de status em sua área de atuação acadêmica e técnica, caso mantenha ambas. Por isso os direitos morais, aqui, ganham um vulto tão importante, enquanto os direitos patrimoniais têm alterada sua forma de resguardo. Adotando o entendimento de Vicente (2005, p.14-18), habilitam-se duas formas de se garantir a percepção de remuneração ao autor: o sistema de compensação equitativa e o de gestão coletiva. O primeiro é calcado no modelo adotado pela União Europeia, com reflexos no direito tributário, em que se fixa uma taxa embutida no preço final ao consumidor de equipamentos capazes de reproduzir cópias digitais. O segundo, de controle estatal, é formatado por intermédio de uma agência reguladora de direitos autorais.

A circulação da obra do autor no ambiente virtual faz que muito mais pessoas o conheçam, acessem outros trabalhos de sua autoria e o utilizem como fonte de pesquisa em suas próprias produções acadêmicas, eis que, por intermédio de um único acesso, de um único download, diversas pessoas podem lê-lo. Hoje, grande parte desse tipo de literatura circula por meio de artigos científicos publicados, de forma gratuita, em revistas específicas e em anais de congressos que, em sua maciça maioria, são disponibilizados em versão impressa e digital, muitas vezes o sendo em versão exclusivamente digital, pois ultimamente os conselhos editoriais têm preterido a versão impressa.

O autor científico, pela internet, pode ter seu conhecimento e seu nome difundidos aos mais diversos lugares, às mais diversas culturas e a todos os usuários da rede que tiverem acesso a seu conteúdo. Dessa forma, poderá ser requisitado a palestrar, a ministrar aulas e cursos e a conduzir pesquisas, atraindo mais clientes - caso trabalhe como um técnico em sua área, além de se dedicar à academia -, tudo por meio da divulgação de baixo custo proporcionada pelo compartilhamento de suas obras nesse ambiente virtual. 
A publicação de artigos científicos, por si só, normalmente não remunera o autor. De fato, é o prestígio que suas publicações trazem que se revela como a grande paga por seu esforço. Trata-se de valor que vai sendo agregado a seu curriculum a cada obra que conclui. E não poderia ser diferente. A cultura e o conhecimento que o intelectual adquiriu ao longo da formação escolar e universitária, como indivíduo e ator social, como profissional e acadêmico, deve ser sustentável: nada mais socialmente justo do que retribuir à sociedade conhecimentos que adquiriu dela e nela, sem olvidar do resguardo aos seus direitos patrimoniais. E esses podem ser efetivados de maneira tão justa e prática como a própria disponibilização de suas obras o é em bits: basta que se criem mecanismos legais para sua viabilização.

\section{O compartilhamento livre de obras científicas na internet como ferramenta capaz de trazer benefícios simultâneos para os autores e para o interesse público}

Ao analisar o retorno auferido pelo autor de uma obra científica ante seu leitor, percebe-se quão positivo é o compartilhamento desse tipo de material na rede, ao possibilitar o acesso, especialmente, aos usuários acadêmicos. Amplamente utilizado é o conceito da internet e do livre compartilhamento de arquivos como uma ameaça social pronta a destruir toda a cultura e o estímulo às obras por dificultar a garantia dos direitos dos autores. No entanto, essa imagem vai-se desmitificando à medida que vão-se encontrando alternativas para a remuneração dos autores, de forma efetiva, como o são a gestão coletiva de direitos e a compensação equitativa.

Os avanços tecnológicos possibilitaram o surgimento da época do imediatismo em que se vive, tendo-se tudo ao alcance de um "clic". Dessa forma, o parâmetro entre o interesse público e os direitos privados, outrora delimitado, perde seu sustento, enfrentando uma nova era de misturas e quebras dogmáticas. Nesse sentido, relativamente aos avanços trazidos com a modernidade, o primeiro autor destas linhas (Adolfo, 2008, p.49) já teve oportunidade de indagar se podem os modelos jurisprivados, heranças de séculos, ser ainda aproveitados em face da complexa realidade do tempo atual: sobreviverão no futuro ou estão fadados ao desaparecimento? Entende-se que sim, que os modelos ultrapassados sobreviverão, mas sofrerão ajustes e adaptações capazes de criar novas diretrizes, e é nesse sentido o presente entendimento. Há a possibilidade do livre compartilhamento de materiais científicos beneficiando o interesse coletivo sem causar prejuízos aos autores. Cria-se o início de uma nova cultura ciberespacial, um novo meio de vida em que, segundo Trivinho (1998, p.28-9), o modelo social válido passa a ser aquele encontrado e reforçado pela tela catódica e por toques digitais vigorando como dispositivos de entrada para a vida na era informática. $\mathrm{O}$ mundo real ingressa, portanto, na esfera virtual, tornando-se o novo real, de forma que a legislação deve ser compatível com os novos métodos de troca de conhecimento e conteúdo. 
Um dos grandes problemas do Brasil consiste em ser um país conservador no que pertine às limitações dos direitos autorais, seguindo a Convenção de Berna, sem atentar à compatibilidade do ordenamento objetivo com os avanços da tecnologia. A cópia privada no Brasil retrocedeu no tratamento às limitações dos direitos autorais com a promulgação da Lei n.9.610, de 1998. Nos dizeres de Ascensão (1997, p.157), a cópia privada é uma manifestação do princípio da liberdade do uso privado. Entretanto, na legislação autoral atual, que pende de iminente reforma no tocante às limitações aos direitos de autor, o legislador preferiu não seguir a trilha que o legislador constitucional traçou - mirando o interesse público, acabando como retrógrada em relação à sua antecessora Lei n.5.988, de 1973 que, no inciso II do artigo 49, permitia a cópia privada de um exemplar para uso não comercial, da integralidade da obra, sem necessidade de autorização do titular dos direitos autorais.

Já na redação da lei em vigor o legislador inova, optando por suprimir a limitação da cópia integral, passando a permitir apenas a reprodução, em um só exemplar e para uso privativo do copista, sem visar lucro, de pequenos trechos da obra, o que suscita diversas interpretações. Acrescenta, ainda, que tal cópia pode ser efetuada apenas pelo beneficiário, excluindo uma pluralidade de eventuais destinatários.

Enfim, a proposta de alteração da Lei n.9.610, de 1998, após a consulta pública levada a cabo pelo Ministério da Cultura, em pouco avança, fomenta polêmica entre os setores da sociedade envolvidos e atrai olhares de descrédito quanto à preservação do interesse público. O inciso I do artigo 46, nos dizeres da proposta, permite a reprodução da obra nessas condições: por qualquer meio ou processo, amplitude em que se entende estar incluído o ambiente digital; em uma cópia apenas, o que carece de efetividade, dado o fato de não se proporcionarem mecanismos de controle que contabilizem quantas cópias um usuário da internet baixou em sua máquina; por pessoa natural, restrição que não se encontra na lei em vigor, o que impede a cópia por uma coletividade, como uma universidade ou grupo de alunos; para seu uso privativo, o que também impede o acesso plural, e não comercial, que nada inova; de obra legitimamente obtida, excetuando as obtidas por meio de locação, ponto que apresenta novidade, assim como o é a parte que permite a cópia desde que realizada a partir de exemplar de obra publicada de forma legal. Percebe-se ainda que os novos dispositivos sobre a cópia privada não tratam de forma explícita a reprodução feita a partir de exemplares obtidos por comodato, como ocorre nas bibliotecas, tratando apenas dos exemplares obtidos em locadoras.

Cabe um olhar mais aprofundado na busca da intenção real presente na redação do anteprojeto em comento: pretende-se apenas resguardar os interesses dos titulares dos direitos autorais, na figura das editoras, ou preservar os direitos autorais dos pesquisadores e professores que elaboram uma obra científica? Ao se revelar tão restritivo na questão das limitações aos direitos de autor, especificamente no inciso I do artigo 46 da Lei Autoral, por certo está de costas ao in- 
teresse público: não o está enxergando, ao menos não em primeiro plano. Também é importante que seja definida a intenção dos próprios autores. A primeira indagação a ser feita ao doutrinador científico sobre a real intenção contida ao publicar uma obra deveria dizer respeito ao tipo de retorno pretendido por ele ao se dedicar a escrever. Parece adormecido o tão óbvio entendimento de que o autor de obras científicas busca, prima facie, ser reconhecido em sua área de atuação e, num segundo momento, contribuir para a evolução da sociedade por meio dos resultados de suas pesquisas e estudos.

Errônea é a interpretação no sentido de retirar o mérito dos autores científicos ao referir que a esses não seriam devidos os direitos autorais. Ao contrário, ao disponibilizar livremente uma obra na internet, o direito moral do autor permanece intocado, tendo a forma de oferta de suas obras, por enfocar o interesse público, certamente, influência apenas na esfera dos direitos patrimoniais. Tal ascendência deve revelar-se positiva uma vez que a diminuição dos custos de produção com impressão e distribuição poderá fazer que o autor venha a perceber remuneração em valores superiores àquela do modelo convencional de editoração.

Ora, um autor de obras literárias como romance ou ficção, normalmente, cria para sobreviver do fruto de seu trabalho, faz disso seu meio de sustento; já o objetivo do autor de livros técnicos e científicos é a busca e distribuição do conhecimento, não só para si, mas para a coletividade; ou seja, este último pretende compartilhar suas descobertas com aqueles que também buscam o conhecimento, criando uma rede de trocas, enriquecendo cada vez mais a cultura e contribuindo com o avanço da sociedade. A criação, a manutenção e a ampliação dessa rede é, hodiernamente, facilitada pela internet.

O fato de os usuários da internet terem à sua disposição a íntegra dos trabalhos científicos para download, sem que isso configure crime de contrafação e sem precisarem de autorização do titular dos direitos, diferindo do sistema físico, culminará num impacto muito grande no meio acadêmico, e isso, certamente, contribuirá para que a formação acadêmica alcance padrões de qualidade mais elevados. Machado \& Ortellado (2006, p.11) demonstram que o acesso aberto desse tipo de obra, em certas áreas do conhecimento, chega a 1.000\% de diferença em comparação ao impacto proporcionado pelo acesso tradicional. A disponibilização acessível de obras científicas na internet contribuiria, ainda, como um filtro, deixando-se à margem de acesso as publicações de pouca qualidade, fazendo que o interesse público seja diretamente beneficiado pela implementação gradual de uma padronagem de alto nível.

Aqui, considera-se adequado fazer uma comparação pontual com o sistema do software livre, que não significa, diretamente, a disponibilização de um programa de computador gratuito, mas acessível a todos. Esse sistema é desenvolvido levando-se em consideração o interesse público. Cerdeira (2004, p.29) vincula a utilização do software livre ao princípio da eficiência, enfatizando que, 
na busca do interesse social, o poder público não pode perder de vista a maximização dos resultados e a minimização dos custos. Ou seja, não há como afrontar os resultados inestimáveis auferidos pelo interesse público ante a disponibilização de obras na internet, de forma mais aberta.

São elogiáveis os progressos já visualizados, como a obrigatoriedade de os alunos de mestrado e doutorado de universidades federais autorizarem a publicação de suas dissertações e teses em local apropriado para esse fim (como em www.dominiopublico.com.br), sustentados que foram seus estudos por todos os brasileiros que, assim, são os beneficiários diretos de ditas investigações, ou como o projeto que noticia Bahia (2011) de que a presidenta Dilma anunciará, na tradicional Feira do Livro de Porto Alegre, em sua edição de 2011, a publicação de livros de literatura no país a um custo final ao consumidor de R\$ 10,00. No entanto, são avanços pontuais que, certamente, reclamam novas discussões e ampliações.

\section{Considerações finais}

Por todo o exposto, tem-se por nítido que é falsa a concepção de que o compartilhamento gratuito de obras intelectuais na internet acarreta tão somente prejuízos ao autor, privilegiando apenas o interesse público em detrimento do privado. Ao contrário do que aparece como dogma no meio editorial e acadêmico, o aludido compartilhamento enseja que tanto os autores quanto a coletividade sejam beneficiados à medida que os Direitos Autorais daqueles sejam garantidos pela norma e viáveis na eficácia.

Defende-se, pois, a reforma legislativa para que uma simples e única cópia integral para uso privado e não comercial deixe de fazer do copista o autor de um ato ilícito. Diante do cenário social brasileiro, em vista de a ocupação dos bancos universitários ser feita cada vez mais por estudantes oriundos de classes sociais de baixo poder aquisitivo, propõe-se que a Lei Autoral seja adaptada para permitir que uma coletividade - como uma turma de alunos de pós-graduação ou uma universidade inteira - possa baixar e reproduzir, na integralidade se assim o desejar, e para qualquer suporte hábil, obras didáticas, técnicas e científicas, sem finalidade lucrativa, independentemente de autorização do autor. Dessa forma, estaria resguardado o interesse público atinente aos direitos à educação e ao acesso à informação e à cultura, insculpidos na Carta Constitucional brasileira.

Para viabilizar a eficácia dos direitos autorais, mormente aqueles de feição patrimonial, sugere-se a adoção do sistema de compensação equitativa, inspirado no modelo praticado pela União Europeia, em que se atribua uma taxa embutida no preço de equipamentos capazes de reproduzir cópias digitais e, também, a gestão coletiva estatal, por intermédio de uma agência reguladora de direitos autorais.

Como demonstrado, o baixo custo de produção da obra posta ao acesso dos usuários da internet, por afastar a necessidade dos serviços editoriais de impressão e comercialização, traz o benefício aos autores de colocarem a si e a 
ela em contato mais direto com o consumidor, tornando bem mais ágil o acesso deste ao conhecimento, e o daqueles às novas oportunidades profissionais. $\mathrm{O}$ autor ainda se beneficia com o destaque de seu status em seu meio de atuação, o que valoriza sua carreira, projeta-o como referência a seus leitores e confere-lhe destaque junto a seus pares.

Resta ultrapassado, nos ditames do Estado Democrático e Social de Direito que foi eleito, admitir um direito autoral que não atente ao interesse social. A ampliação das limitações dos direitos autorais deveria estar elencada como uma das principais alterações na Lei Autoral que está sendo gestada no Brasil. Em sua ausência, essas linhas pretendem, pois, contribuir para a reflexão acerca da (re)construção de um novo direito autoral, alinhado com a matriz principiológica constitucional brasileira, opondo-se ao atual tratamento das limitações aos direitos autorais na legislação. Conforme sucintamente demonstrado neste trabalho, na pretensão de servir como ponto de partida para futuras abordagens, na crítica do inciso I do artigo do Digesto Autoral que está tomando forma, o problema das limitações aos direitos autorais merece apreciações que esclareçam suas vicissitudes.

Referências

ADOLFO, L. G. S. Obras privadas benefícios coletivos: a dimensão pública do Direito Autoral na Sociedade da Informação. Porto Alegre: SafE, 2008.

. O Direito Autoral clássico é estimulo ou desestímulo à concretização plena da dignidade da pessoa humana por meio do direito à educação? Boletim da Faculdade de Direito, Coimbra: Universidade de Coimbra, 2009.

ARONNE, R. Por uma nova hermenêutica dos direitos reais limitados: das raízes aos fundamentos contemporâneos. Rio de Janeiro: Renovar, 2001.

. Propriedade intelectual e direitos reais: um primeiro retomar da obviedade.

In: _. (Org.) Direito civil-constitucional e teoria do caos: estudos preliminares. Porto Alegre: Livraria do Advogado, 2006. p.93-130.

ASCENSÃO, J. de O. Direito autoral. Rio de Janeiro: Renovar, 1997.

2002.

. Direito da internet e da sociedade da informação. Rio de Janeiro: Forense,

. Direito fundamental de acesso à cultura e direito intelectual. In: SANTOS, M. J. P. dos. (Org.) Direito de autor e direitos fundamentais. São Paulo: Saraiva, 2011. p.9-44. 
AVANCINI, H. B. Direitos humanos fundamentais na sociedade da informação. In: . BARCELlOS, M. L. L. (Org.) Perspectivas atuais do direito da propriedade intelectual. Porto Alegre: Edipucrs, 2009. p.45-68.

BAHIA, C. Best-seller. Zero Hora, Porto Alegre, 21 set. 2011, p.21.

BAUMAN, Z. O mal-estar da pós-modernidade. Rio de Janeiro: Jorge Zahar, 1998.

BOFF, S. O.; BORTOLANZA, G. O direito de autor e o desafio da internet: liberdade versus responsabilidade. Diritto Brasiliano, online, 25 nov. 2010. Disponível em: <http://www.diritto.it/docs/30653-o-direito-de-autor-e-o-desafio-da-internet-liberdade-versus-responsabilidade\#>. Acesso em: 17 set. 2011.

BRASIL. Constituição da República Federativa do Brasil de 1988. Brasília, 5 de outubro de 1988. Disponível em: <http://www.planalto.gov.br/ccivil_03/constituicao/ constitui\%C3 \%A7ao.htm>. Acesso em: 10 set. 2011.

Código Civil de 1916 - Lei n.3.071, de 1o de janeiro de 1916. Diário Oficial da União, Rio de Janeiro, 5 jan. 1916. Disponível em: <http://www.jusbrasil.com. br/legislacao /103251/codigo-civil-de-1916-lei-3071-16>. Acesso em: 19 set. 2011.

. Lei n.5.988, de 14 de dezembro de 1973. Regula os direitos autorais e dá outras providências. Diário Oficial da União, Brasília, 18 dez. 1973. Disponível em: <http:// www.jusbrasil.com.br/legislacao/109137/lei-5988-73>. Acesso em: 19 set. 2011.

Senado Federal. Lei n.9.610, de 19 de fevereiro de 1998. Altera, atualiza e consolida a legislação sobre direitos autorais e dá outras providências. Diário Oficial da União, Brasília, 20 fev. 1998. Disponível em: <http://www6.senado.gov.br/legislacao/ListaPublicacoes.action ?id=148431>. Acesso em: 17 set. 2011.

CABRAL, P. Direito autoral: dúvidas e controvérsias. São Paulo: Rideel, 2009.

CASTELLS, M. A sociedade em rede: a era da informação. São Paulo: Paz e Terra, 2001. v.l.

CERDEIRA, P. C. Copyleft e software livre: uma opção pela Razão - Eficiência Tecnológica, Econômica e Social - II. Revista da ABPI, São Paulo, n. 71, jul./ago. 2004.

COELHO, P. Pirateiem meus livros. Folha de S.Paulo, São Paulo, 30 maio 2011. Disponível em: <http://paulocoelhoblog.com/2011/05/30/pirateiem-meus-livros/>. Acesso em: 17 set. 2011.

DUVAL, H. Violações dos direitos autorais. Rio de Janeiro: Borsoi, 1968.

HAMMES, B. J. (Coord.). Ensino do Direito do Autor. In: SEMINÁRIO INTERNACIONAL SOBRE DIREITO DO AUTOR, 1. São Leopoldo, ago. 1994. Anais... São Leopoldo: Ed. Unisinos, 1994.

LEITE, E. L. Direito de autor. Brasília: Brasília Jurídica, 2004.

LEMOS, A. Cibercultura como território recombinante. In: MARTINS, C. D. et al. (Org.) Territórios recombinantes: arte e tecnologia - debates e laboratórios. São Paulo: Instituto Sérgio Motta, 2007. p.35-48.

LEMOS, R. Direito, tecnologia e cultura. Rio de Janeiro: Ed. FGV, 2005.

LÉVY, P. Cibercultura. São Paulo: Editora 34, 1999.

MACHADO, A.; ORTELLADO, P. Direitos autorais e o acesso a publicações científicas. Revista Adusp, online, São Paulo, n.37, ago. 2006. 
NEGROPONTE, N. A vida digital. 2.ed. São Paulo: Companhia das Letras, 1997. OLIVER, P. Direitos autorais da obra literária. Belo Horizonte: Del Rey, 2004.

REIS, J. R. dos. O direito de autor no constitucionalismo contemporâneo: considerações acerca de sua função social. In: ADOLFO, L. G. S.; MORAES, R. (Coord.) Propriedade intelectual em perspectiva. Rio de Janeiro: Lumen Juris, 2008. p.151-61.

SILVEIRA, N. A propriedade intelectual e as novas leis autorais. São Paulo: Saraiva, 1998.

TRIVINHO, E. Redes, ciberspaço e sociedade. In: MARCONDES FILHO, C. et al. Vivências eletrônicas: sonhadores e excluídos. São Paulo: NTC, 1998. p.21-32.

VICENTE, D. M. Cópia privada e sociedade da informação. 2005. Disponível em: <http://www.estig.ipbeja.pt/ ac_direito/Cprivada.pdf>. Acesso em: 18 set. 2011.

WACHOWICZ, M. Direitos autorais e o domínio público da informação. In: SANTOS, M. J. P. dos. (Org.) Direito de autor e direitos fundamentais. São Paulo: Saraiva, 2011. p.200-26.

RESUMO - É de conhecimento geral que os modernos avanços das ciências da tecnologia, na era digital, facilitam a troca de informações e de dados, contribuindo para a disseminação da cultura e para o desenvolvimento da educação e da cidadania e conferindo status e prestígio aos autores. Este estudo propõe a reflexão sobre a mudança do paradigma de um direito autoral concebido no modelo liberal oitocentista, incrustado na Lei Autoral brasileira em vigor e em seu anteprojeto de alteração, que prevê, de forma limitada, o compartilhamento de arquivos de cunho científico no âmbito virtual. Deseja-se, portanto, contribuir para o debate da reforma da Lei n.9.610, de 1998, demonstrando que há mais benefícios do que prejuízos aos autores científicos quando têm suas publicações disseminadas de forma integral e acessível na internet.

PALAVRAS-CHAVE: Direitos autorais, Interesse público, Compartilhamento, Obra científica, Internet, Sociedade informacional.

ABSTRACT - It is well known that modern advances in science technology in the digital age facilitate the exchange of information and data, contributing to the spread of culture and the development of education and citizenship, conferring status and prestige to the authors. This study proposes a reflection of the paradigm shift from a model conceived in the Copyright nineteenth-century liberal, embedded in Brazilian copyright law in force and in its draft amendment, which provides a limited file sharing as part of a scientific in the virtual field. It is a goal to finally contribute to the debate of the reform of Law No. 9610/98, demonstrating that there are more benefits than harm to 
scientific authors have their publications disseminated in a comprehensive and accessible on the Internet.

KErWORDS: Copyrights, Authors rights, Technology sharing, Scientific work, Internet, Informational society.

Luiz Gonzaga da Silva Adolfo é advogado, doutor em Direito pela Unisinos. Presidente da Comissão Especial de Propriedade Intelectual da OAB/RS na gestão 2010/2012. Membro da Associação Portuguesa de Direito Intelectual (APDI). Professor do PPG em Direito da Universidade de Santa Cruz do Sul (Unisc). Professor dos cursos de Direito da Universidade Luterana do Brasil (Ulbra) (Gravataí) e do Instituto Brasileiro de Gestão de Negócios (IBGEN) (Porto Alegre/RS). Idealizador e coordenador do curso de Especialização Lato-Sensu em Direito da Propriedade Intelectual pela Esade - Laureate Iternational Universities (Porto Alegre/RS).

@ - gonzagaadolfo@yahoo.com.br

Ieda Rocha é mestranda em Ciências Sociais com ênfase em Organizações, pela PUCRS. Estudante de especialização lato-sensu em Direito da Propriedade Intelectual pela Esade - Laureate International Universities. @ - contato@iedarocha.com.br

Laura Luce Maisonnave é advogada. Estudante de especialização lato-sensu em Propriedade Intelectual pela Esade - Laureate International Universities; estudante de especialização lato-sensu em Processo Civil pela Universidade Anhanguera-Uniderp/ LFG-SP. @-laura@leao.adv.br

Recebido em 13.10.2011 e aceito em 9.2.2012. 